\title{
APPLICATION OF FEFLOW FOR THE SIMULATION OF GROUNDWATER FLOW AT THE TIRNAVOS (CENTRAL GREECE) ALLUVIAL BASIN AQUIFER SYSTEM
}

\author{
Koukidou I. ${ }^{1}$, Panagopoulos A. ${ }^{2}$ \\ ${ }^{1}$ Aristotle University of Thessaloniki, Inter-departmental of Biology, Geology and Civil Engineering, "Eco- \\ logical water quality and management at a river basin level”, 54124 Thessaloniki, Greece, \\ cookie@bio.auth.gr \\ ${ }^{2}$ National Agricultural Research Foundation, Land Reclamation Institute, 57400 Sindos, Thessaloniki, \\ Greece,panagopoulosa@gmail.com
}

\begin{abstract}
FEFLOW is a relatively new simulation code that was applied and tested systematically for the first time in Greece at Tirnavos alluvial basin, which is part of the eastern Thessaly plain. The aim of this exercise is to apply and test the applicability and versatility of FEFLOW in the simulation of groundwater flow of the Tirnavos basin aquifer system, which is located in eastern Thessaly-central Greece. From the compilation and calibration of the mathematical model, it can be concluded that FEFLOW is a very powerful tool with many practical applications and capabilities. Application of FEFLOW at Tirnavos basin was successful. As deduced by field data analysis, groundwater resources of the study area are overexploited, a fact which bears negative effects not only for the study area, but also for the surrounding area, which is much greater in extent. This fact was well reproduced in the simulation. It is therefore of utmost importance to rationally manage regional groundwater resources aiming at aquifer restoration (quantity and chemical quality) and the environmental protection of both the aquifer system and the depended and interrelated ecosystems, in accordance to the water related EC Directives.
\end{abstract}

Key words: FEFLOW, numerical modelling, groundwater flow, simulation, hydrogeology, Thessaly.

\section{Introduction}

Mathematical models were presented for the first time at the end of 19th century (Anderson and Woessner, 1992), however, nowadays they have been developed greatly and their use has expanded considerably, because of their capability to manage large volumes of data, make infinite combinations and repeat the process as many times as needed. Hence, they offer high degrees of reproducibility in results and in parallel allow for exhaustive analysis and examination of alternative hydrogeological setup configurations and water resources management plans. In this development also contributed the establishment of national laws and European Directives that create a comprehensive frame of sustainable management for the long-term protection of all waters (surface, transient, underground and coastal) and ecosystems.

In their efforts to comply with the 2000/60/E.C. Water Framework Directive (WFD), and the 2006/118/E.C. Groundwater Daughter Directive (GWDD), member states of the European Com- 


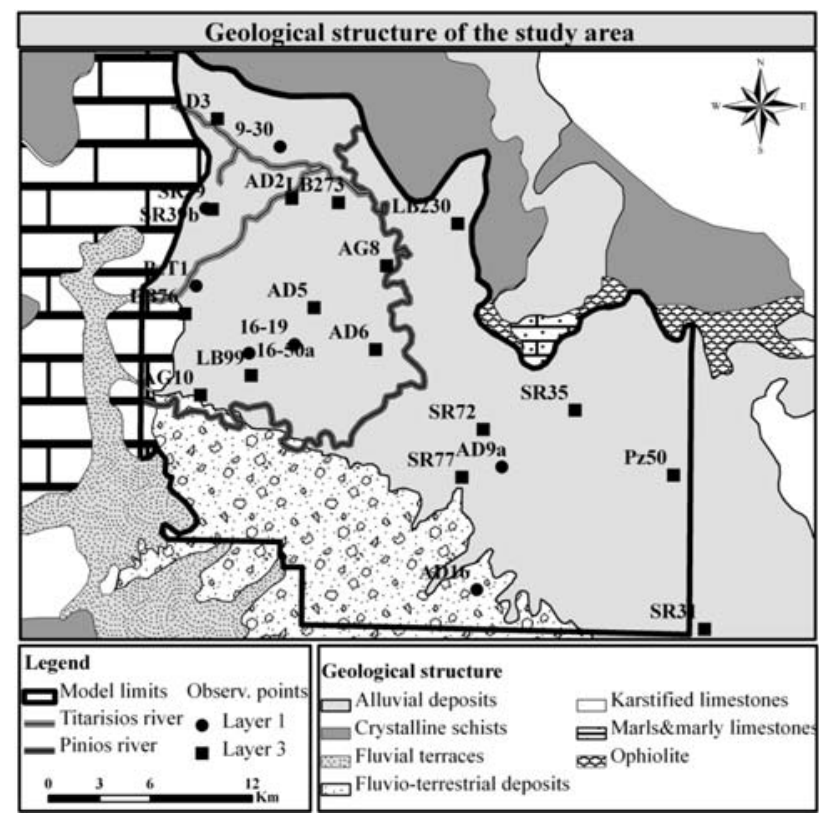

Fig. 1: Geological setup of the Tirnavos alluvial basin.

munity used numerical models in order to produce sound, trustworthy and easy to review and implement water resources management plans.

One of the available numerical models for the simulation of groundwater flow is the relatively new, finite element code, FEFLOW. Its systematic application has been attempted for the first time in Greece, at Tirnavos basin, an area where water has particular importance for its economic growth and social welfare, and which faces quality and quantity problems with its water resources.

Groundwater resources of the study area cover the largest part of water demands of eastern Thessaly plain. The main productive activity is agriculture, and $14 \%$ of the domestic agricultural products originate from this region. Consequently, for the development of this area water resources have to be managed in such a way, so as to avoid overexploitation and to ensure that the essential quantities of water for irrigation and domestic consumption are not exceeded.

\section{Geological-hydrological characteristics}

The alluvial basin of Tirnavos forms the north-eastern part of the eastern Thessaly plains of central Greece and administratively belongs to Larissa Prefecture. Hydrologically, it belongs to Pinios river basin and River Pinios and Titarisios flow through the study area. It is an active tectonic basin that is filled with Neogene and Quaternary deposits and is bounded by formations of the Pelagonian tectonic zone (Mountrakis, 1985), as illustrated in figure 1.

Carboniferous-Middle Triassic gneiss and schists of the Pelagonian zone crop out along the northern edge of Tirnavos plain and from the bedrock of the basin. To the west the basin is delineated by the karstified Tirnavos-Damasi-Koutsohero crystalline limestones (Sogreah, 1974). Two major springs emerge at the contact of the karstified system with the alluvial deposits. The Mati spring is used for irrigation, while the Agia Anna spring provides most of the domestic water demands of the adjacent town of Tirnavos (Constandinidis, 1978). 
Neogene marls and marly limestones crop out along the south-western and north-eastern margins of the alluvial basin. The presence of these formations, especially so the former known as mid-thessalian hills, is important because they separate hydrogeologically the eastern from the western Thessaly plain (Electrowatt, 1967).

Alluvial deposits that fill the basin are of fluvio-lacustrine to fluvio-torrential origin. Typically, the alluvial sediments are characterized by considerable lithological variations, and consist of intercalations of sand, gravel and clays (Compagnie Generale de Geophysique, 1972). The aquifer system of Tirnavos has been formed within the alluvium. It consists of a lower thick, predominantly confined aquifer, and a superimposed unconfined aquifer (Electrowatt, 1967).

Agriculture is the dominant economic activity and cultivated farms expand to some $86 \%$ of the spatial extend of the basin. Out of this percentage, only $32 \%$ are non-irrigated fields, thus account for xeric cultivations. It may easily be deduced that irrigation is the dominant water user in the region and accounts for some $90-95 \%$ of total water demands, whilst domestic water supplies take up only $3 \%$ of the annually abstracted volumes of water. Groundwater essentially covers all water demands through abstractions from numerous shallow wells and deep boreholes and surface water contributes only a minor percentage (Panagopoulos et al., 2006; Karyotis et al., 2008).

\section{Methods}

\subsection{Conceptual model}

Existing data and analyses from previous studies were considered for the compilation of the conceptual and mathematical models (Panagopoulos 1996, Hatzidiamantis et al., 2009; Syllaios et al., 2009). For the compilation of the conceptual model, hydrochemical, piezometric and water budget data were used. Based on these data, the aquifer system of Tirnavos consists of a lower thick (400m) predominantly confined aquifer, and a thin (40-70m) superimposed unconfined aquifer. The two aquifers in the centre of the basin are separated by a confining clay layer. The thick clay layer is present in the central area, but thins out and disappears towards the edges, where the upper and lower aquifers unify (Panagopoulos et al., 1995; Panagopoulos, 1996).

Lateral crossflow from the karst is the most important source of recharge to the aquifer system and also crossflow from the river Titarisios gorge via its highly permeable fluvio-torrential cone (Panagopoulos et al., 1995). Lateral crossflows from the river Pinios gorge do exist but are of minor importance compared to the previously discussed sources.

Minor crossflows from the crystalline bedrock along the north-eastern margin of the basin and also crossflows from the tertiary deposits of the Mid-Thessalian hills in the south-southwest of the study area recharge the aquifer system. Infiltration of precipitation also occurs and accounts for a small fraction (5-15\%) of the system's recharge (Panagopoulos et al., 1995). During summer time irrigation returns also occur and contribute to the system's recharge (Panagopoulos et al., 2008).

The aquifer system of Tirnavos extends to the east-southeast towards which a significant lateral crossflow exists. Discharge is also indicated at the northern margin of the study area, where the river Pinios flows out of the Tirnavos basin (Panagopoulos et al., 1995). Apart from the natural discharge areas, artificial discharge also exists in the form of abstractions mainly for irrigation but also for domestic needs and for the small industrial units in the study area, through numerous shallow wells and deep boreholes (Katsilouli et al., 2004). It has to be stated that the study area is the main recharge zone of the southeastern extension of the aquifer system, hence groundwater abstractions from the 
Tirnavos aquifer system strongly influence water budget of the southeastern extension of the system.

In previous studies (Panagopoulos, 1996), a general water balance of the alluvial system was calculated for year 1973 (a period of time during which the aquifer system would be in dynamic steady state conditions). Water balance calculations resulted that total inflow to the system is $188,100 \mathrm{~m}^{3} / \mathrm{d}$ and total outflow from the system is $183,000 \mathrm{~m}^{3} / \mathrm{d}$. The calculated water balance served as a reference and guideline to the initial calibration of the designed groundwater flow model of the study area and as such it proved to be essential.

\subsection{Numerical model}

FEFLOW is a fully integrated 3D finite element model, which excels in cases that involve complex geological structures, unsaturated flow, density-dependent flow (saltwater intrusion) or thermal convection (FEFLOW, 2009). It is used not only for fluid, mass and heat transport, but also for saltwater infiltration simulation, for both porous and discontinuity (under conditions) media (FEFLOW, 2009).

The available element types include the quadrilateral and the triangular elements, where groundwater level is calculated in each node (Diersch, 1998). FEFLOW's finite element approach allows the user to perform local mesh refinements only in the areas of interest thus avoiding creation of excessive number of elements.

Amongst the advantages of the finite element method is the ability to represent key features of the modelling domain (geological contacts, boundary conditions, main stress zones, etc) with high precision (Raptanova et al., 2007). Out of all capabilities offered by FEFLOW, this paper focuses on the groundwater flow in porous media.

\subsection{Model compilation and calibration}

The system comprises of three layers or 4 slices, according to FEFLOW terminology. The modelling domain has an aerial extent of about $741.1 \mathrm{~km}^{2}$ and comprises of a 6-nodal triangular prismatic mesh that contains 501,726 mesh elements and 335,948 mesh nodes.

In order to better simulate the main evolution mechanisms that control groundwater flow, the resulting mesh has been refined in the areas of interest, i.e. the margins of the study area, rivers and wells, so that boundary conditions can be set more precisely.

\subsubsection{Boundary conditions}

It is suggested that under ideal conditions boundaries of the modelling domain coincide with natural hydrogeological boundaries of the region (Anderson and Woesner, 1992; Panagopoulos, 1996). Thus, the northern margin comprises the crystalline bedrock, where a small groundwater crossflow occurs. Tirnavos karst system was set as the western margin, from where the alluvial system is recharged primarily. The southern margin was set to the Mid-Thessalic hills, along which the system receives a small fraction of recharge as earlier discussed. No natural hydrogeological boundary may be identified along the eastern part of Tirnavos alluvial basin. To overcome this oddity the boundary was assumed along a line striking at almost N-S direction that coincides to the documented uplift of the bedrock. This uplift results in seasonal hydraulic cut off of the Tirnavos basin from its southeastern extension (Panagopoulos, 1996).

Boundary conditions of third type (Cauchy), using the "transfer function" of FEFLOW (FEFLOW, 2009), were assigned to all boundaries. This type of condition was selected because it provides the 


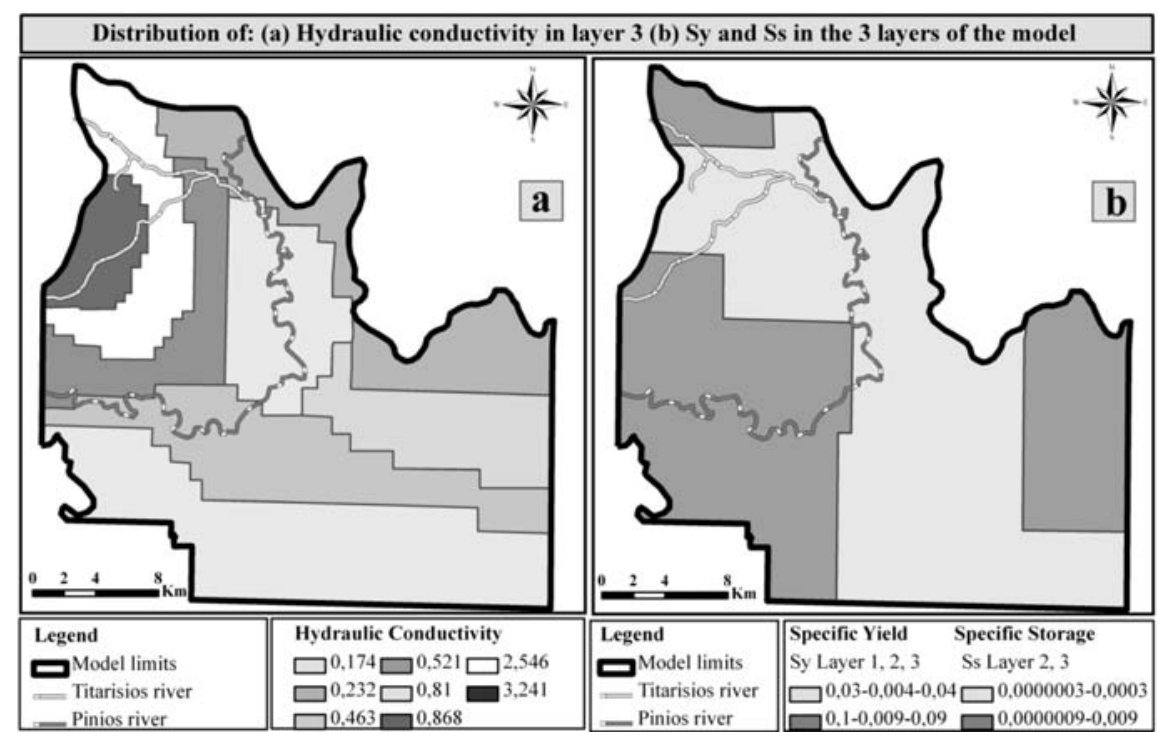

Fig. 2: a) Distribution of hydraulic conductivity in the third layer of the model $\left(10^{-4} \mathrm{~m} / \mathrm{sec}\right)$ and $\left.\mathrm{b}\right)$ distribution of specific yield (Sy) and specific storage (Ss) $(1 / \mathrm{m})$ in the three layers of the model.

maximum degree of freedom to the flow domain within the modelling area, thus allowing for unbiased simulations. River Pinios and Titarisios were also simulated using Cauchy boundary conditions.

\subsubsection{Stresses}

Production wells that operate mainly in the central part of the modelled area were set as discharge points. For assigning the abstractions, the mean yields for year 1973-1974 for the steady state conditions was used, while for the transient state conditions, data from the period between 1973 and 1994 were considered. The "wells function" of FEFLOW was used to set the abstractions, which corresponds to Neumann boundary conditions.

Direct recharge from precipitation, was based on the characteristics of the soil cover and the lithological characteristics of the upper aquifer. Five discrete zones were separated on the basis of afore mentioned criteria. The infiltration rate "i", was expressed as the percentage depth rate of rainfall " $R$ " and was assigned in each zone. Data from the meteorological stations of Larissa and Tirnavos that are located within the core of the modelling domain were used.

\subsubsection{Distribution of hydraulic parameters}

For the compilation of the mathematical model, the definition of hydraulic conductivity, specific storage and specific yield are required. The hydraulic parameter values that were used as input data in the designed model have been obtained from an older study (Panagopoulos, 1996), which was based on the pumping test analyses and on the geological and lithological characteristics of the system. The spatial distribution and the actual values initially assigned were reviewed during the calibration process.

Hydraulic conductivity values range from 0.0003 to $3.24110^{-4} \mathrm{~m} / \mathrm{sec}$ as indicatively illustrated in figure $2 \mathrm{a}$ for layer 3 . Specific yield values range from 0.004 to 0.1 and specific storage values range from $310^{-6}$ to $910^{-4} 1 / \mathrm{m}$ (Fig. 2b). 
Table 1. Range of values used for the hydraulic parameters K, Sy and Ss.

\begin{tabular}{|l|c|c|c|c|c|c|}
\hline & \multicolumn{2}{|c|}{ Layer 1 } & \multicolumn{2}{c|}{ Layer 2 } & \multicolumn{2}{c|}{ Layer 3 } \\
\hline & Min & Max & Min & Max & Min & Max \\
\hline $\begin{array}{l}\text { Hydraulic conductivity } \\
(\mathbf{1 0}\end{array}$ & 0.116 & 1.505 & 0.000029 & 0.002083 & 0.174 & 3.241 \\
\hline Specific yield & 0.03 & 0.1 & 0.004 & 0.009 & 0.04 & 0.09 \\
\hline Specific storage $\left.\mathbf{( m}^{-\mathbf{1}}\right)$ & & & 0.0000003 & 0.0000009 & 0.0003 & 0.0009 \\
\hline
\end{tabular}

In general, hydraulic parameters' values are lower to the central and eastern parts of the modelling domain and considerably lower in the confining clay layer compared the two aquifer units (Tab. 1). FEFLOW's convention regarding parameters' units has been followed in this presentation.

\subsubsection{Calibration-verification of the model}

The compiled model was initially calibrated under dynamic steady state (DSS) conditions and subsequently under transient state (TS) conditions. The following parameters were considered during the calibration process: water balance, divergence between measured-computed piezometric levels at selected observations points, shape of computed piezometric curves compared to the piezometric maps produced on the basis of field data and selected statistical parameters. For DSS calibration the hydrological year of 1973-1974 was selected, because it is characterized by average rainfall and no extreme stresses imposed on the system. A total of 26 observation points (Fig. 1) were employed (7 for the unconfined and 19 for the confined aquifer). A maximum of $3 \mathrm{~m}$ deviation between modelled and monitored heads was assumed acceptable at this stage of calibration.

For the calibration in TS conditions the selected period was 1973-1994, because during this period a satisfactory volume of integrated data could be reclaimed. Hydrographs of 17 observation points (Fig. 1) were used ( 7 for the unconfined and 10 for the confined aquifer) for this calibration. A maximum of $5 \mathrm{~m}$ deviation between modelled and monitored heads was assumed acceptable at this stage of calibration. Due to lack of data and the fact that the system is not highly stressed, a single stress period was assumed up to year 1984, following which 2 stress periods (winter-summer) are set per year.

Verification of the model was also performed using existing field data for the period 1994-2000 (Hatzidiamantis et al., 2009; Syllaios et al., 2009).

\section{Results and conclusions}

\subsection{Results}

The calibrated piezometry for both layers (unconfined and confined aquifers) matches well with the compiled piezometric maps for the examined period of time, especially in the core of the modelled domain, for both calibration stages (DSS, TS), as illustrated in the indicative figures $3 \mathrm{a}$ and $3 \mathrm{~b}$.

The water balance produced by the model in DSS conditions agrees well with the reference water balance estimated using available field data (Panagopoulos, 1996; Hatzidiamantis et al., 2009).

For DSS calibration the graph of measured versus computed piezometric data resulted in an insignificant deviation from target set of only three observation points (Fig. 4). 


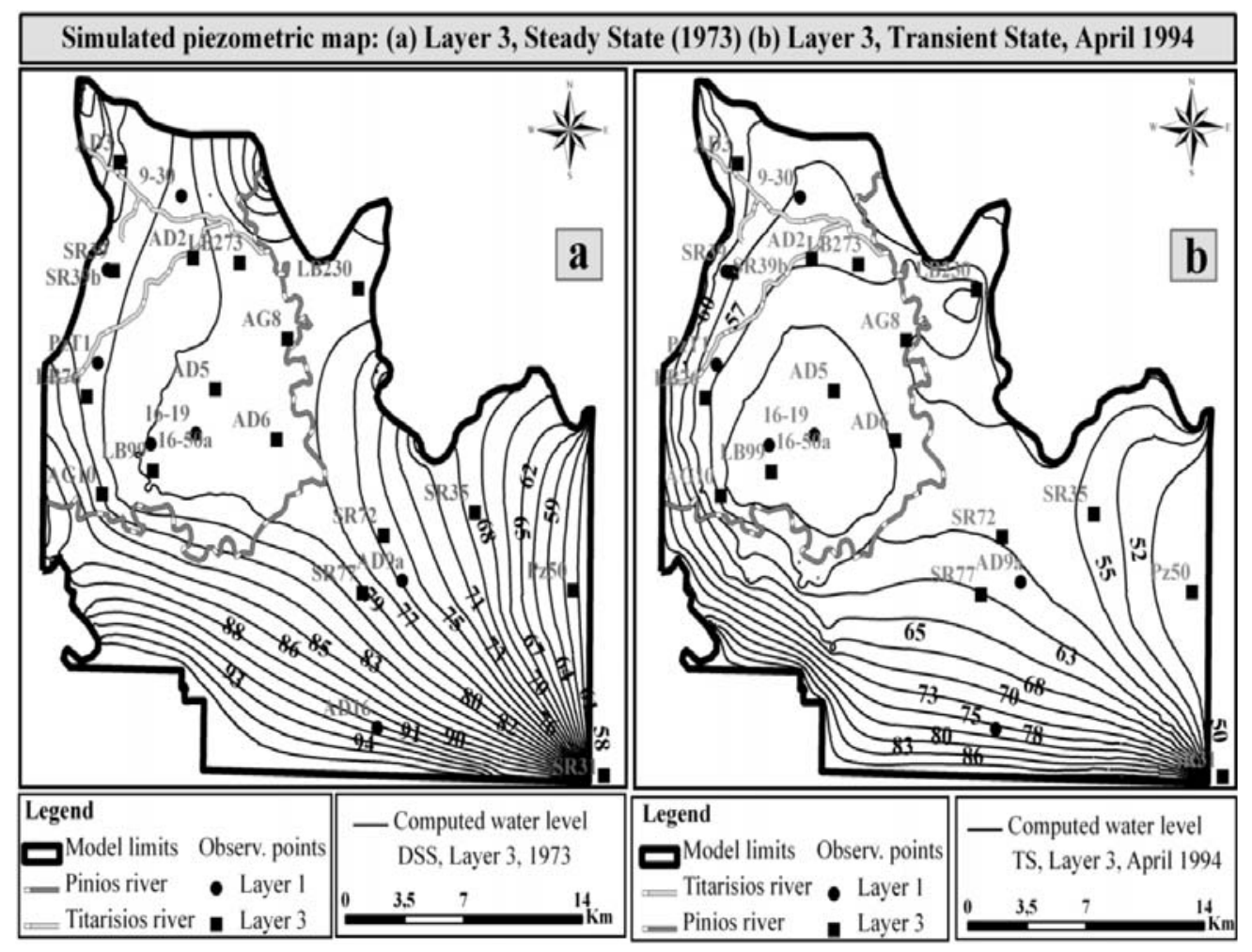

Fig. 3: a) Produced piezometric map for DSS conditions, layer 3, in meters a.o.d. b) Produced piezometric map for TS conditions, layer 3 in meters a.o.d.

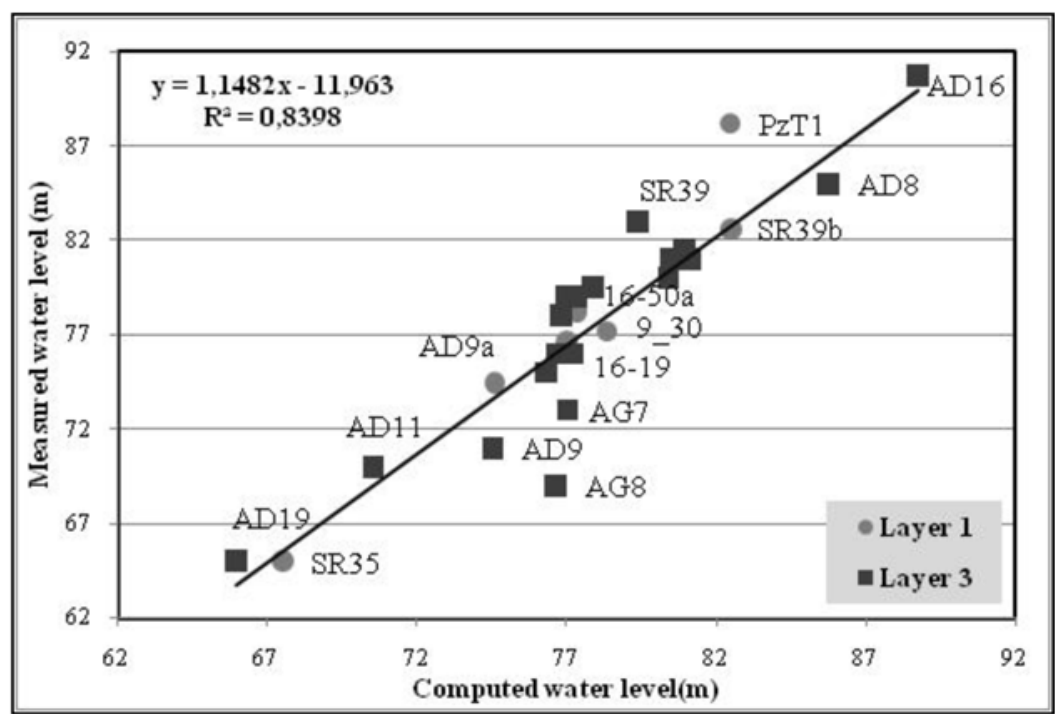

Fig. 4: Graph of measured-computed groundwater level at the observation points of the first and the third layer, DSS calibration. 


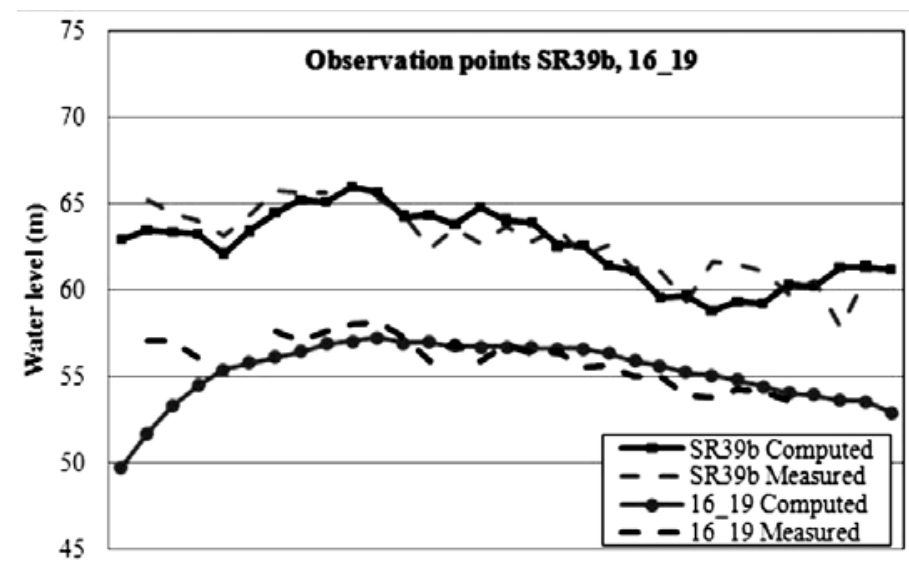

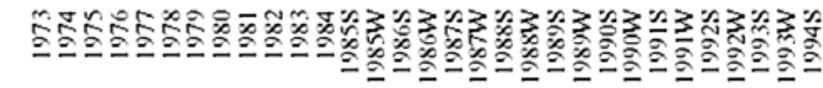

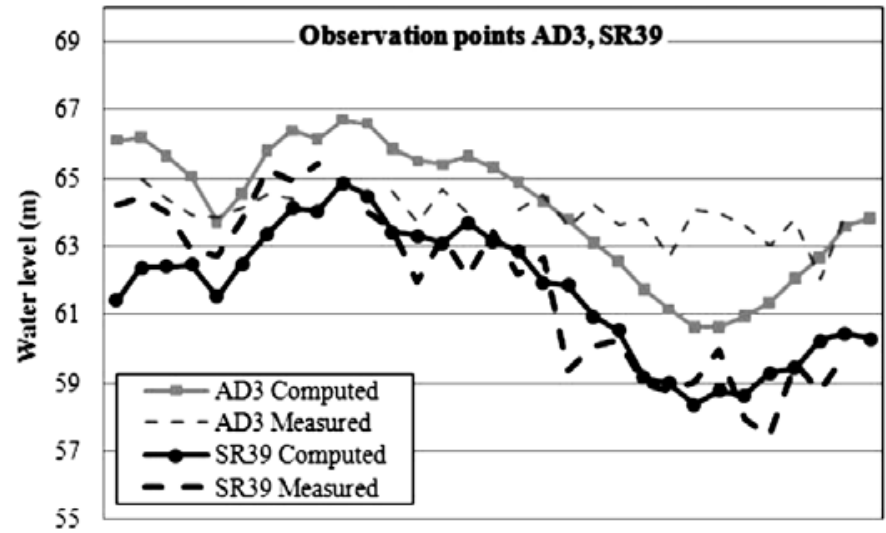

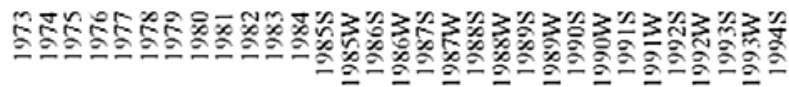

Fig. 5: Comparative hydrographs at selected observation points during the TS calibration period.

Table 2. Selected statistical parameters of calibrated model.

\begin{tabular}{|l|c|c|c|c|}
\hline & Mean Error & $\begin{array}{c}\text { Mean Absolute } \\
\text { Error }\end{array}$ & $\begin{array}{c}\text { Root Mean } \\
\text { Square }\end{array}$ & St. Deviation \\
\hline Dynamic Steady St. & & & & \\
\hline Layer 1 (unconfined aq.) & 0,71 & 1,19 & 2,23 & N/A \\
\hline Layer 3 (confined aq.) & $-1,04$ & 3,68 & 3,56 & N/A \\
\hline Transient St. & & & & \\
\hline Layer 1 (unconfined aq.) & $-0,22$ & 1,67 & 2,09 & 1,56 \\
\hline Layer 3 (confined aq.) & 0,31 & 3,02 & 4,52 & 3,72 \\
\hline
\end{tabular}




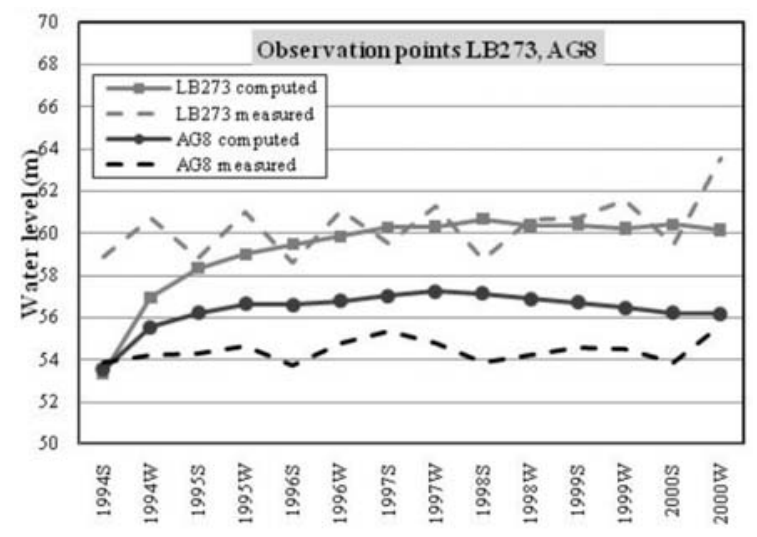

Fig. 6: Comparative hydrographs at selected observations points over the verification process.

Study of hydrographs at the selected monitoring points suggests that the results obtained from the calibrated model in TS conditions matches well with field data as illustrated in selected comparative hydrographs of figure 5 .

The calculated statistical parameters for both steady and transient state calibration are acceptable as presented in Table 2.

Following calibration, the model was verified using field data for a period of 6 years as explained in a previous section of this paper (1994-2000). Results of this exercise suggest that the model can reproduce the main evolution mechanisms reasonably well. This is illustrated in figure 6 which presents indicatives comparative hydrographs at selected observation points.

\subsection{Conclusions and discussion}

Application of FEFLOW in the alluvial groundwater system of Tirnavos basin showed that it is a seamless, functional and reliable numerical model that enables accurate representation of boundary conditions and the system's geometry. Results of the calibrated and verified groundwater flow model allow for a deep insight in the groundwater flow mechanisms of the basin. The compiled model clearly demonstrated the need for immediate actions to be taken in the direction of restoration and protection of the aquifer system. Based on the calibrated model, a set of alternative water resources management scenarios may be designed and reliably tested in order to select the optimal water resources management scheme that will balance environmental protection and socio-economic welfare of the region, in accordance to the EC Directives.

Previous attempts to model the study area were also successful, using MODFLOW, which is a simpler finite difference code (Panagopoulos, 1996). However, FEFLOW provides a much more accurate representation of the aquifer's geometry, hence allows for better simulation of boundary conditions and focusing on specific parts of the modelling domain. As a result, the finite element approach presented in this paper provides a higher quality result, compared to that obtained from finite difference models.

It has to be stressed however, that due to the structure of the modelling code, FEFLOW is a much more demanding package compared to MODFLOW $\mathrm{n}$ terms of both required input data and also computational power. It is therefore suggested that perspective users should balance out the extra data and time required setting up and calibrating a FEFLOW model against the potential improved sim- 
ulation accuracy obtained given the appropriate data, prior making a definitive decision on the modelling code to be selected. Last but no least, the initial investment required to obtain FEFLOW might be a limiting factor, as this is considerably higher than a finite difference code.

\section{Acknowledgments}

Results presented in this paper originate from a Thesis elaborated in the framework of the inter-departmental postgraduate programme "Ecological water quality and management at a river basin level" of the Aristotle University of Thessaloniki. The study was hosted and supported scientifically and technically at the National Agricultural Research Foundation-Land Reclamation Institute at Sindos-Thessaloniki.

\section{References}

Anderson, M., Woessner, W., 1992. Applied groundwater modeling. Simulation of flow and advective transport. Academic Press, London 381pp.

Compagnie Generale de Geophysique, 1972. Reconnaissance par prospection electrique dans la Plaine de Thessalie (Grece). Grenoble: CGG.

Constandinidis, D., 1978. Hydrodynamique d' un systeme aquifere heterogene. Hydrogeologie de la Thessalie Orientale. Ph.D. thesis, Universite Scientifique et Medicale de Grenoble, 288pp.

Diersch, H.G., 1998. FEFLOW interactive, graphics-based finite-element simulation system for modeling groundwater flow, contaminant mass and heat transport processes. WASY Institute for Water Resources Planning and System Research Ltd., Berlin, Germany, 401-425.

Electrowatt Engineering Services, 1967. Development of the plains of Thessaly. Preliminary study and feasibility report. Ministry of Public Works, Athens, (in Greek).

FEFLOW 5.4, 2009. Finite element subsurface flow and transport simulation system. User's manual. WASY Institute for Water Resource Planning and Systems Research Ltd., Berlin, Germany, 202pp.

Hatzidiamantis, A., Zalidis, G., Alexandridis, Th., Gakis, K., Galanis, G., Partozis, A., Panagopoulos, A., Panoras, A., Arampatzis, G., Hatzigiannakis, E., Vrouchakis, J., Alexiou, G., Kalfountzos, D., Kotsopoulos, S., 2009. Study for irrigation water pricing at Pinios River Basin (Tirnavos sub-basin). Phase C.

Karyotis, Th., Charoulis, A., Panagopoulos, A., Tziouvalekas, M., Georgiou, Th., Karyoti, K., Mitsimponas, Th., 2008. Groundwater quality and threshold values for irrigation in the river Basin of Pinios, Greece. Session: Soil and Water - Practical Applications. Abstracts, Int. Conference "EUROSOIL 2008”, Vienna, 333pp.

Katsilouli, Ir., Karyotis, Th., Georgiou, Th., Mitsimponas, Th., Panagopoulos, A., Panoras, A., Pateras, D., Haroulis, G., Argyropoulos, G., Toulios, M., 2004. Nitrates in soils and water originated from agricultural sources: a case study in Thessaly, central Greece. Proceedings 12th Nitrogen Workshop “Controlling nitrogen flows and losses", Wageningen Academic Publishers, 447-448.

Mountrakis, D., 1985. Geology of Greece. University Studio Press, Thessaloniki, 207pp (in Greek).

Panagopoulos, A., 1996. A methodology for groundwater resources management of a typical alluvial aquifer system in Greece. Ph.D. thesis, University of Birmingham, Birmingham, 251pp.

Panagopoulos, A., Karyotis, A., Georgiou, Th., Tsitouras, Al., 2006. Groundwater natural background levels and threshold definition in the Eastern Thessaly groundwater body (Pinios River Basin, Central Greece). Greek Case Study Report, BRIDGE Project, 23 pp.

Panagopoulos, A., Lloyd, J., Fitzsimons, V., 1995. Groundwater evolution of the Tirnavos alluvial basin, central Greece, as indicated by hydrochemistry. $3^{\text {rd }}$ Hydrogeological Conference of the Hellenic Chap- 
ter of IAH, Heraklion, Crete, 232-244.

Panagopoulos, A., Pechlivanidou, S., Vrouhakis, Y., Karyotis, Th., Arampatzis ,G., Hatzigiannakis, E., Panoras, A., 2008. Determining reference conditions for groundwater bodies using simple historical data; the case of eastern Thessaly, Greece. E-Proc. 36th Int. Congress of the International Association of Hydrogeologists, Toyama, 1-7.

Rapantova, N., Grmela, A., Vojek, D., Haril, J., Michlek, B., 2007. Groundwater flow modelling applications in mining hydrogeology, 532pp.

Sogreah. "Final report". Groundwater development project of the plains of Thessaly, (in Greek). Athens: Land Reclamation Services of Greece, 1974.

Syllaios, N., Zalidis, G., Alexandridis, Th., Galanis, G., Christoforou, M., Strati, S., Cherif, I., Partozis, A., Panagopoulos, A., Vrouchakis, J., Pechlivanidou, S., Alexiou, G., Kalfountzos, D., Kotsopoulos, S., 2009. Study for irrigation water pricing at Pinios River Basin (Tirnavos sub-basin). Phase B. 